\title{
Association between metabolic diseases and the culling risk of high-yielding dairy cows in a transition management facility using survival and decision tree analysis
}

\author{
M. Probo, ${ }^{* 1,2}$ O. Bogado Pascottini, $\dagger^{1}$ S. LeBlanc, $\dagger$ G. Opsomer, $\ddagger$ and M. Hostens $\ddagger$ \\ *Veterinary Teaching Hospital, Department of Veterinary Medicine, University of Milan, via dell'Università 6, 26900 Lodi, Italy \\ †Population Medicine, Ontario Veterinary College, University of Guelph, N1G 2W1 Ontario, Canada \\ ‡Department of Reproduction, Obstetrics and Herd Health, Faculty of Veterinary Medicine, Ghent University, Salisburylaan 133, \\ 9820 Merelbeke, Belgium
}

\section{ABSTRACT}

The objective of this study was to assess the association between individual metabolic diseases $(\mathrm{MD})$ and multiple $\mathrm{MD}(\mathrm{MD}+)$ in the transition period $( \pm 3 \mathrm{wk}$ relative to calving) and the culling risk in the first 120 $\mathrm{d}$ in milk (DIM) in Holstein-Friesian dairy cows. Health records from a transition management facility in Germany with 1,946 calvings were analyzed in a 1 -yr cohort via survival analysis and a decision tree model. The recorded $\mathrm{MD}$ were milk fever $(\mathrm{MF})$, retained placenta (RP), metritis (METR), ketosis (KET), displaced abomasum (DA), twinning (TWIN), and clinical mastitis (MAST). The overall culling within 120 DIM was $18 \%$. The 120 DIM culling risk for healthy cows $(64.8 \%$ of the total) was $13 \%$, whereas it was $25 \%$ for MD (24.5\%) and $33 \%$ for MD+ (10.7\%) cows. The 120 DIM culling risk (\%) for each MD and MD+, respectively, was 34.6 and 48 for $\mathrm{MF}$ and $\mathrm{MF}+, 15$ and 31.5 for $\mathrm{RP}$ and $\mathrm{RP}+$, 9.4 and 22.2 for METR and METR+, 30.7 and 37.3 for KET and KET+, 56.1 and 46.8 for DA and DA+, 30.3 and 34 for TWIN and TWIN+, and 36.6 and 27.8 for MAST and MAST +. Moreover, the incidence risk (\%) for each MD and MD+, respectively, was 4 and 2.6 for $\mathrm{MF}$ and $\mathrm{MF}+, 1$ and 2.8 for $\mathrm{RP}$ and $\mathrm{RP}+, 8.7$ and 6 for METR and METR+, 4.5 and 6.1 for KET and KET+, 0.8 and 2.4 for DA and DA+, 1.7 and 2.7 for TWIN and TWIN+, and 3.6 and 1.8 for MAST and MAST+. Setting the healthy cows as the referent, the 120 DIM hazard ratios (HR) for culling were MD 2.1, MD +2.9 , MF 3.3, MF+ 4.6, RP+ 2.7, METR+ 1.8, KET 2.6, $\mathrm{KET}+3.3$, DA 5.5, DA+ 4.5, TWIN 2.8, TWIN+ 3.0, MAST 3.1, and MAST +2.3 . According to both decision tree and random forest analyses, MF was the most

Received January 10, 2018

Accepted June 25, 2018.

${ }^{1}$ These authors contributed equally to this manuscript.

${ }^{2}$ Corresponding author: monicaprobo@gmail.com significant disease influencing survival, followed by DA, MAST, METR, and TWIN. In conclusion, the presence of MD or MD+ during the transition period was associated with increased culling risk in the first 120 DIM. The culling hazard was greater when an MD was complicated with another MD. In this study performed in a well-managed large farm, uncomplicated cases of $\mathrm{RP}(\mathrm{HR}=1.2)$ and METR $(\mathrm{HR}=0.7)$ did not have an influence on the 120 DIM culling risk. Interestingly, both decision tree and random forest analyses pointed to MF and DA as main culling reasons in the first 120 DIM in the present dairy herd.

Key words: transition period, metabolic disease, survival analysis, decision tree

\section{INTRODUCTION}

The identification of early predictors for the productive life of cows is of great interest to improve dairy herds' profitability. The availability of quality replacement heifers, appropriate management to mitigate transition cow disease risk, and good culling decision making profoundly influence the productivity and profitability of the herd. An elevated culling rate is associated with high replacement costs, whereas a low culling rate might impair milk production, reproduction, and genetic improvement (Hadley et al., 2006). Culling decisions are made based on cow factors as well as external factors that are often specific to the herd or even country (De Vries, 2017). In this regard, Fetrow et al. (2006) suggested that culling can occur voluntarily due to low production, cow aggression, and sales to other dairy farms or involuntarily due to disease, injury, infertility, or death. Metabolic diseases (MD) are significant causes of involuntary culling (Esslemont and Kossaibati, 1997; Essl, 1998; Seegers et al., 1998; Bell et al., 2010; Pinedo et al., 2010; Chiumia et al., 2013). They occur mainly during the transition period, defined as the time from $3 \mathrm{wk}$ precalving until $3 \mathrm{wk}$ 
postcalving (Sundrum, 2015). This period is characterized by marked changes in the endocrine status and a reduction in feed intake (Grummer, 1995), resulting in a negative energy balance of varying duration and intensity. Concomitantly, endocrine immunosuppression and environmental stressors such as group changes during the transition period make the dairy cows prone to develop infectious diseases (Mulligan and Doherty, 2008; Ingvartsen and Moyes, 2015). Due to the combination of the aforementioned factors centralized around parturition, the transition period is characterized by an elevated risk for MD.

Most often, the annual culling risk among dairy cows is reported to be about 22 to $25 \%$ (Esslemont and Kossaibati, 1997; Hare et al., 2006; Bell et al., 2010), but in production systems with a great supply of replacement heifers (due to high reproductive performance or lower rearing costs) it reaches 35 to 36\% (De Vries, 2017; Haine et al., 2017a). A recent study (Dubuc and DenisRobichaud, 2017) identified prevalence alarm levels of postpartum diseases based on association with a high prevalence of postpartum culling. However, reports on the association between specific disease and culling rates are scarce and mostly published before 2000 (Milian-Suazo et al., 1988; Beaudeau et al., 1995; Gröhn et al., 1998), whereas more recent literature often focuses on 1 specific transition disease (e.g., metritis: Dubuc et al., 2011; Wittrock et al., 2011; or mastitis: Haine et al., 2017b).

As comprehensively discussed by Mulligan and Doherty (2008), transition diseases are often complexly linked to each other. Unravelling these interactions on different aspects of dairy cow management has become a research area in its own. In a previous study, Hostens et al. (2012) used a lactation curve modeling approach on high-quality milk production data from a transition management facility (Fetrow et al., 2004) to study the interactive effects of transition diseases on milk production. Recently, data mining techniques such as decision trees have regained popularity through their ease of gaining insight in complex operational research (Rokach and Maimon, 2014). These methods provide variable importance measures that have been acknowledged as valuable tools in applied sciences such as genetics and bioinformatics (Holzinger, 2015). These importance measures may help us better understand and visualize interactions, including the relative importance of interconnected disease events.

Thus, the objectives of the current study were (1) to retrospectively evaluate the incidence of uncomplicated (single) and complicated (multiple; MD+) cases of MD and (2) use survival analysis and decision tree modeling to assess the order of importance of MD on survival in the first 120 DIM in high-yielding Holstein-Friesian dairy cows in a transition management facility.

\section{MATERIALS AND METHODS}

\section{Study Design}

This retrospective observational study consisted of the analysis of health records collected during a 1-yr period (April 2009 to April 2010). Data records were obtained from a dairy herd located in Mecklenburg-Vorpommern, Germany, by using the on-farm computer system Dairy Comp 305 (Valley Ag Software, Tulare, CA). The herd consisted of approximately 2,450 Holstein-Friesian cows during the timeframe of data collection (herd size constantly expanding during this time). The average milk production per lactation $(305 \mathrm{~d})$ was $11,085 \mathrm{~kg} /$ cow (3.64\% milk fat, $3.32 \%$ milk protein). Transition cow management was as described by Hostens et al. (2012). Briefly, heifers and multiparous cows (40 and 42 d before expected parturition, respectively) were transferred to specially designed transition facility barns. These barns comprised sand-bedded freestall pens with a maximum of 32 animals per group, and special efforts were made to closely monitor the transition cows. Cows and heifers were housed separately until 10 to 21 DIM. All animals were fed a TMR once daily according to their transition status (far-off, close-up, and freshcow diets). Between 10 and 21 DIM, cows and heifers were moved to freestall milking barns, fed a TMR (in groups) according to the production level of the pen, and milked twice daily.

\section{Transition Diseases: Diagnosis and Treatments}

A fresh cow protocol was established immediately after parturition involving oral administration of 500 $\mathrm{mL}$ of propylene glycol (Bernd-Dieter, Dusseldorf, Germany) in $50 \mathrm{~L}$ of warm $\left(37-38^{\circ} \mathrm{C}\right)$ water to all cows. Additionally, all cows with parity $>1$ were provided with $500 \mathrm{~mL}$ of a $38 \%$ calcium borogluconate solution intravenously (Calcilift Forte, Albrecht GmbH, Aulendorf, Germany). All the transition problems (after calving) were diagnosed and treated by specially trained personnel according to specific protocols. The monitored transition problems in this study were milk fever (MF), retained placenta (RP), metritis (METR), ketosis (KET), displaced abomasum (DA), twinning (TWIN), and mastitis (MAST).

Diagnosis of MF was based on clinical signs (within $48 \mathrm{~h}$ of calving): cold ears and extremities, muscular tremor, ataxia, decreased ruminal motility, and incapability of rising. The MF treatment consisted of $500 \mathrm{~mL}$ 
of calcium borogluconate solution (38\%) intravenously for up to 3 consecutive days in case of recumbency. A cow was considered to suffer from RP when the placenta was not expulsed by $24 \mathrm{~h}$ after parturition. Retained placenta per se was not medically treated; however, RP cows were carefully monitored for pyrexia during subsequent weeks.

The diagnosis of METR was made by clinical signs of fetid uterine discharge and pyrexia $\left(>39.5^{\circ} \mathrm{C}\right)$, and systemic illness (toxemia, dullness, anorexia, and so on) in case of severe METR, within 21 DIM (Sheldon et al., 2006). Cows diagnosed with METR were treated intramuscularly with ceftiofur hydrochloride (Excenel RTU, Pfizer Animal Health GmbH, Berlin, Germany) for 3 consecutive days $(2.2 \mathrm{mg} / \mathrm{kg}$ of BW) plus a single intrauterine infusion of oxytetracycline at a dose of 15 $\mathrm{mg} / \mathrm{kg}$ of BW (Oxy-Sleecol $200 \mathrm{LA}$, Albrecht GmbH).

Ketosis was defined as reduced feed intake accompanied by midstream urinary ketone bodies exceeding 500 $\mu \mathrm{mol} / \mathrm{L}$ (Ketostix, Bayer AG, Leverkusen, Germany). Cows with KET were treated differently according to the urinary ketone body concentration: concentrations between 1,500 and 4,000 $\mathrm{mmol} / \mathrm{L}$ were treated with $500 \mathrm{~mL}$ of propylene glycol for 3 consecutive days, and concentrations exceeding $4,000 \mu \mathrm{mol} / \mathrm{L}$ were treated intravenously with $500 \mathrm{~mL}$ of $40 \%$ glucose solution (B. Braun, Melsungen, Germany), $40 \mathrm{~mL}$ of a vitamin B complex (Vitamin B-Komplex, Serumwerk Bernburg, Bernburg, Germany), and an intramuscular injection of dexamethasone at a dose of $0.08 \mathrm{mg} / \mathrm{kg}$ of BW (Rapidexon, Albrecht $\mathrm{GmbH}$ ).

The DA diagnosis was done by the standard method of tympanic resonance ("ping") during percussion of the left flank. Treatment of choice for DA was the "rolland-toggle" method. Recurrent cases were surgically treated with abomasopexy.

Although TWIN is not considered a transition disease or an MD, it is a risk factor associated with other transition diseases. Therefore, due its remarkable importance, TWIN was included as an MD in this study. Like TWIN, MAST is not a transition disease; however, it has been associated with impaired metabolic health by multiple authors (Jánosi et al., 2003; Nyman et al., 2008; Moyes et al., 2009). Consequently, MAST was also included as an MD in this survival study if it was diagnosed within 30 DIM. Cows with clinical signs of MAST (udder inflammation and altered organoleptic characteristics of milk) within 30 DIM were treated with an intramammary application of $88.8 \mathrm{mg}$ of cefquinome sulfate per infected quarter (Cobactan LC, Intervet Deutschland GmbH, Unterschleißheim, Germany) for 3 consecutive days. In case of relapse, cefquinome was additionally applied intramuscularly at a dose rate of $1 \mathrm{mg} / \mathrm{kg}$ of BW (Cobactan 2.5\%, Intervet Deutschland
$\mathrm{GmbH}$ ) in combination with a single intravenous injection of flunixin meglumine at a dose of $2.2 \mathrm{mg} / \mathrm{kg}$ of BW (Finadyne, Intervet Deutschland $\mathrm{GmbH}$ ).

\section{Statistical Analyses}

Descriptive Analysis. Data were initially exported from the on-farm record system of the herd (Dairy Comp 305) to a Microsoft Excel file (Microsoft Corp., Redmond, WA). Descriptive statistical analysis was performed using the function summary of the $\mathrm{R}$ (version 3.3.0; R Core Team, Vienna, Austria) code system. For all subsequent statistical analyses, the cow was considered as the unit of interest. The significance and tendency levels were declared at $P<0.05$ and $P<0.1$, respectively.

Survival Analysis. Initially, univariable survival models (package survival, function survfit) were used to analyze the association between culling (or death) during the first 120 DIM and MD, parity, and season (season of calving). The milk production level was not accounted for because some cows were culled shortly after calving. Next, the association between culling (or death) during the first 120 DIM and each individual MD (TWIN, MF, RP, METR, KET, DA, and MAST) was assessed (stratified by parity). In all cases, the association between the 120 DIM culling (or death) and the MD was evaluated in 2 ways: (1) cows presenting an MD, either complicated or not complicated with another MD, versus healthy cows (2 groups of cows) and (2) cows suffering from a single MD (uncomplicated cases) versus cows suffering from multiple MD simultaneously (complicated cases) versus healthy cows (3 groups of cows). The log-log for each stratum was plotted against the time to cull or death for the KaplanMeier graphs to confirm whether curves were parallel. To estimate the differences between each group of cows, the chi-squared test for each model (package survival, function survdiff) was performed. Also, the univariable hazard ratio for each transition disease was calculated to quantify the instantaneous (constantly proportional) relative risk of culling per unit of time (package survival, function coxph). Multivariable hazard ratio models were computed to assess the confounding effect that parity and season had on MD, MD+, and each MD (by manual stepwise backward elimination). Only variables and first-order interactions with $P$-values $<0.05$ were retained in the final model. A multivariable hazard ratio analysis including all MD separately in a single model was impossible to fit given the high number of categorical variables and interactions, which dropped the distinct number of cows per category.

Decision Tree. Comprehensively, a survival tree (ctree function, package partykit; hierarchically or- 

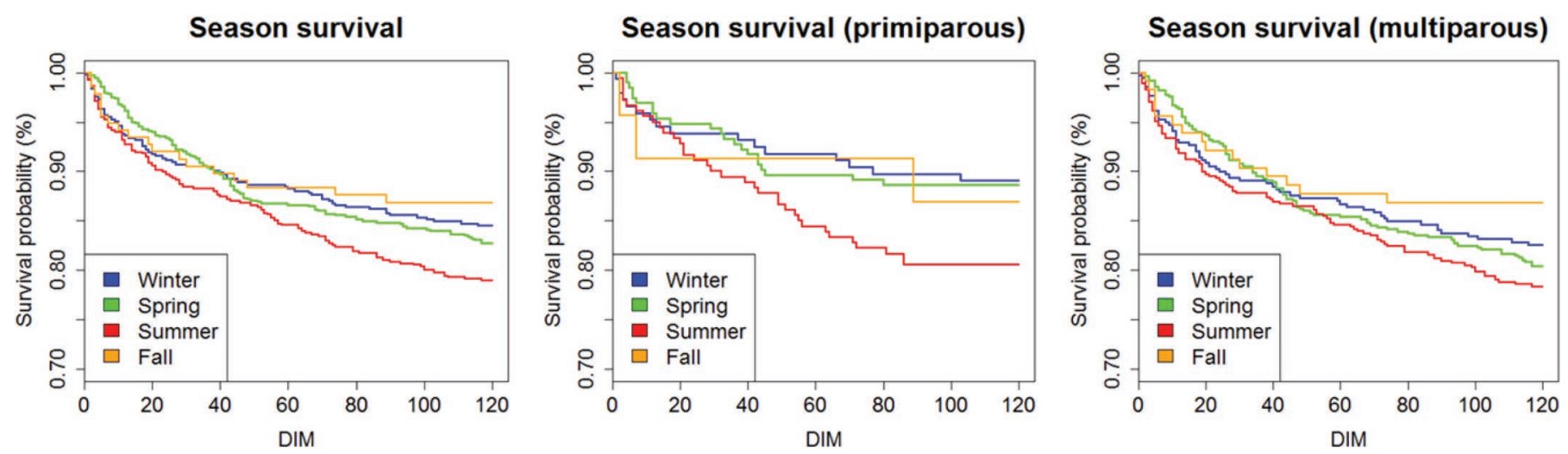

Figure 1. Kaplan-Meier graphs depicting the effect of season on the 120 DIM survival of high-yielding dairy cows. Color version available online.

dered) and a random forest (randomForest function, package randomForest) were built to summarize the effect and to explore the importance of the transition diseases on the culling or death within the first 120 DIM in high-yielding dairy cows. The default parameters were used for the ctree function. Tree tuning parameters were specified for the RF algorithm (Liaw and Wiener, 2002). Sampling was done with replacement. The number of variables randomly sampled as candidates at each split (mtry) was set as the square root of the number of variables in the data set. The number of trees to be grown (ntree) was set at 2,000. The minimum size of the end nodes (nodesize) was set at 1 , the default value for classification (Liaw and Wiener, 2002). The randomForest package (Liaw and Wiener, 2002) is able to calculate measures for variable importance. In this study, the mean decrease in Gini index and mean decrease in accuracy when variables were excluded in turn were used to compute the influence of the predictor variables on the random forest. The direction of the influence of an individual variable on the survival classification was explored using the partialPlot function from the randomForest package (Liaw and Wiener, 2002). The standard out-of-bag error estimate was used as cross-validation for the randomForest function.

\section{RESULTS}

In this study, data collected from 1,946 calvings during a 1-yr period were analyzed. The parity distribution was 27.9 and $72.1 \%$ for first- and older-parity cows, respectively. The 120 DIM culling risk for primiparous cows was $14 \%$ (95\% CI: $10.8-16.6 \%)$, whereas it was $19.2 \%$ (95\% CI: $17.6-20.9 \%)$ for multiparous cows $(P$ $=0.008)$, with an overall culling risk within 120 DIM of $18 \%$ (95\% CI: $15.6-20.2 \%$ ). Summer was the single season with a significant detrimental effect on 120 DIM survival $(P=0.02)$ compared with the other seasons of the year. When stratified by parity, the seasonal effect remained significant for the primiparous animals $(P=$ $0.04)$ but not for the multiparous animals $(P=0.16$; Figure 1).

The incidences of MD (uncomplicated and complicated cases) sorted by parity (primiparous and multiparous) are shown in Table 1 . The survival graphs in Figure 2 depict the 120 DIM survival rates of cows presenting MD (complicated or uncomplicated with another MD) versus healthy cows and of cows suffering from a single MD versus cows suffering from multiple MD simultaneously $(\mathrm{MD}+)$ versus healthy cows. The Kaplan-Meier graphs (Figure 1) illustrate the 120 DIM survival rates for each MD (MF, RP, DA, KET, METR, TWIN, and MAST; uncomplicated or complicated with another MD).

In the multivariable hazard models including parity and season as confounders, multiparous cows that presented MD or MD+ during the transition period were significantly more likely to be culled than primiparous cows (Table 1). Tables 2 and 3 illustrate the individual hazard ratio of each MD (MF, RP, DA, KET, METR, TWIN, and MAST; either uncomplicated or complicated with another MD) on culling in the first 120 DIM (stratified by parity).

Last, the decision tree as illustrated in Figure 3 shows a hierarchical order of the association between culling and each MD disease diagnosed during the transition period in the first $120 \mathrm{DIM}$. The random forest revealed an out-of-bag estimated error rate of $17.8 \%$. The mean decrease in accuracy and the mean decrease in Gini index was largest for DA and MF and for MF and DA, respectively (Figure 4).

\section{DISCUSSION}

Culling decisions are made based on factors belonging to the cow, such as health, milk production, and 
Table 1. Descriptive statistics showing the incidence $[\%(\mathrm{n})]$ of distinct metabolic diseases diagnosed during the transition period of dairy cows

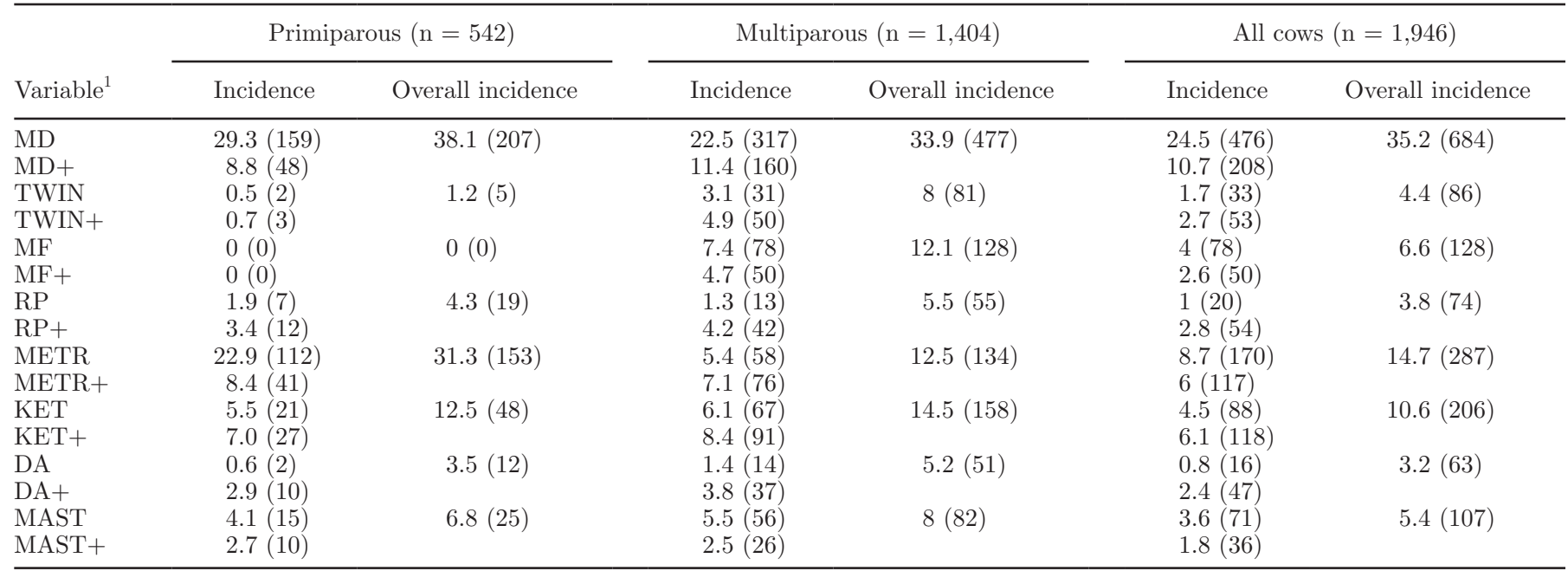

${ }^{1} \mathrm{MD}=$ (any) single metabolic disease; TWIN = twinning; $\mathrm{MF}=$ milk fever; $\mathrm{RP}=$ retained placenta; $\mathrm{METR}=$ metritis; KET $=$ ketosis; $\mathrm{DA}=$ displaced abomasum; MAST $=$ mastitis. $+=$ multiple MD.

reproductive status, but also on external factors such as the availability of replacement heifers given the herd's reproductive performance, parlor capacity, milk and beef prices, land availability, or even country-specific quotas (De Vries, 2017). As in this study, culling reasons are linked to a specific farming context (Martin

\section{Single transition disease survival}

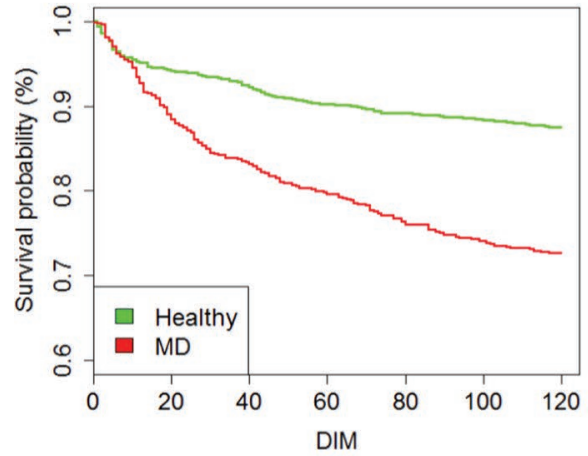

Multiple transition disease survival

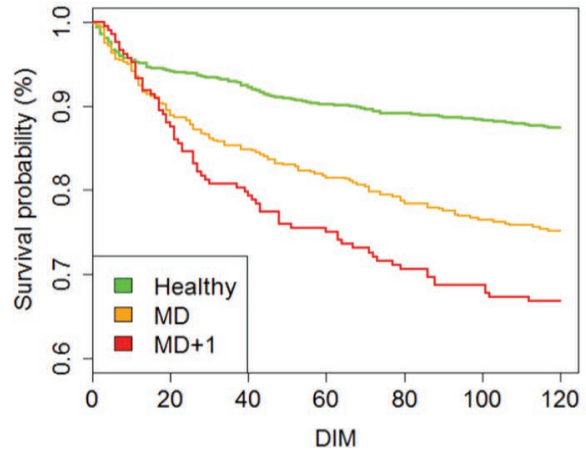

Single transition disease survival (primiparous)

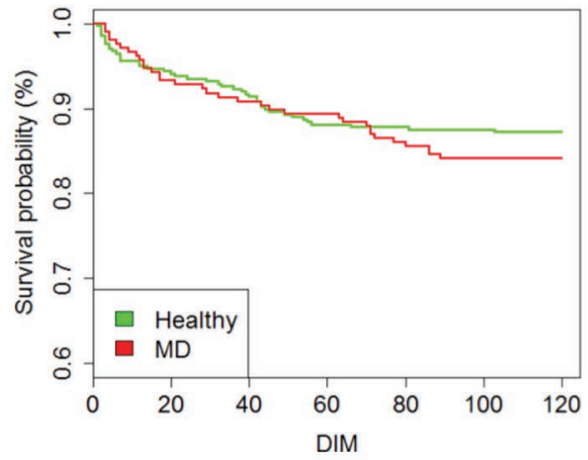

Multiple transition disease survival (primiparous)

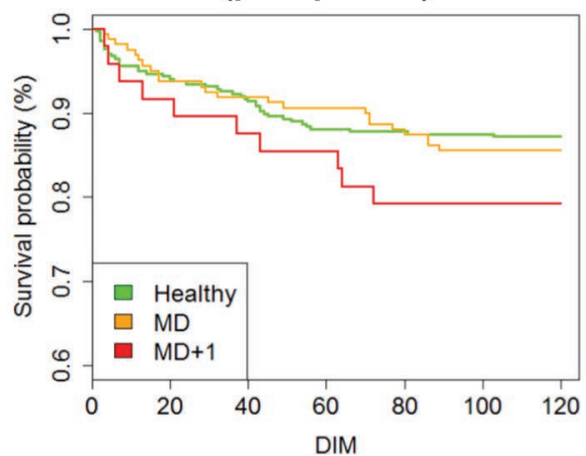

Single transition disease survival (multiparous)

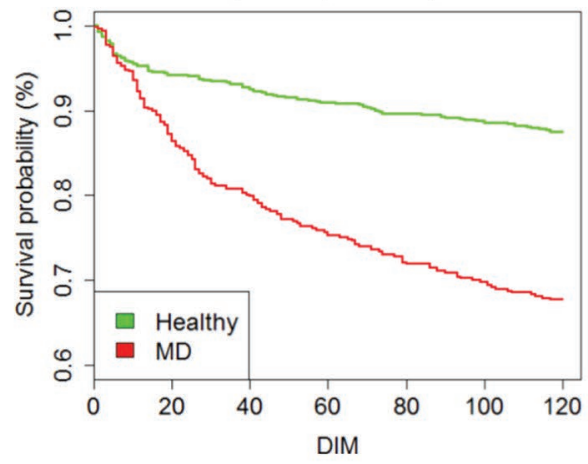

Multiple transition disease survival (multiparous)

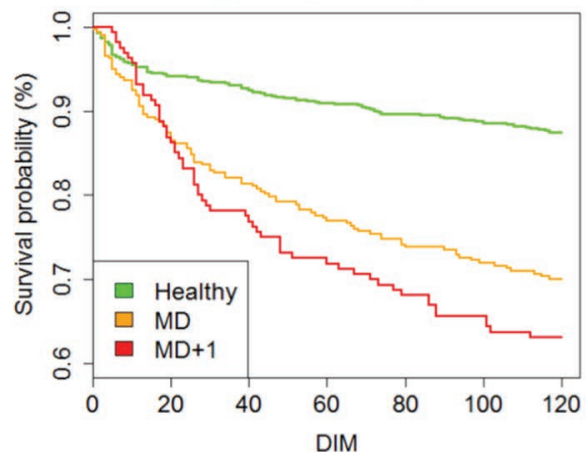

Figure 2. Survival curves showing (first row) the effect of cows presenting any metabolic disease (MD; complicated plus uncomplicated with another MD) versus healthy cows and (second row) the effect of cows suffering from 1 MD (only uncomplicated cases) versus cows suffering multiple MD simultaneously (MD+) versus healthy cows on 120 DIM survival. Color version available online. 
Table 2. The 120-DIM univariable hazard model outcomes of each metabolic disease (complicated plus noncomplicated cases) diagnosed during the transition period in dairy cows

\begin{tabular}{|c|c|c|c|c|c|c|}
\hline \multirow[b]{2}{*}{ Transition disease $^{1}$} & \multicolumn{3}{|c|}{ Primiparous $(\mathrm{n}=542)$} & \multicolumn{3}{|c|}{ Multiparous $(\mathrm{n}=1,404)$} \\
\hline & Hazard ratio $^{2}$ & $95 \%$ CI & $P$-value & Hazard ratio & $95 \% \mathrm{CI}$ & $P$-value \\
\hline TWIN & 3.5 & $0.8-14.9$ & 0.08 & 2.9 & $1.9-4.4$ & $<0.001$ \\
\hline $\mathrm{MF}$ & - & - & - & 3.8 & $2.7-5.3$ & $<0.001$ \\
\hline RFM & 1.1 & $0.6-2.0$ & 0.68 & 1.6 & $1.2-2.1$ & $<0.001$ \\
\hline METR & 0.9 & $0.6-1.2$ & 0.54 & 1.2 & $0.9-1.5$ & 0.059 \\
\hline MAST & 1.6 & $1.1-2.3$ & 0.01 & 1.7 & $1.3-2.0$ & $<0.001$ \\
\hline
\end{tabular}

${ }^{1}$ TWIN = twinning; MF = milk fever; RFM = retention of fetal membranes; METR = metritis; KET = ketosis; DA = displaced abomasum; MAST $=$ mastitis.

${ }^{2}$ Hazard ratio $=$ chances of relative risk (constantly proportional) of culling per unit of time. Hazard ratio healthy $=1$.

et al., 1982), although a recent study from Canada suggested that the herd effect on culling risk is only minor (Haine et al., 2017c). To our knowledge, this is the first study describing the association between MD and culling in a transition management facility, where preventive strategies are adopted to limit the onset of transition diseases, and it could therefore be useful for future comparison with herds with similar management strategies.

Survival analysis has been considered the most appropriate method for the analysis of longitudinal data in dairy research (Beaudeau et al., 1995). However, the timing of diagnosis as well as withdrawal periods due to specific disease treatments can bias the moment of culling and influence survival analysis in early lactation. Such bias, which can be observed in the Kaplan-
Meier plots for MET, DA, and MAST in early lactation ( $<14$ DIM), was minimized by extending the point of analysis substantially beyond the point of diagnosis or treatment.

This study presented an overall culling risk of $18 \%$ by 120 DIM. The parity distribution comprised around one-third of the cows in the first lactation (representing normal herd demographics). The culling risk was significantly higher in multiparous cows $(19.2 \%)$ than in primiparous cows (14\%), which has been described by other authors (Gröhn et al., 1998; Hare et al., 2006). Primiparous cows that calved in summer were at higher risk for being culled within the first 120 DIM. The seasonal effect was not detectable in multiparous cows, which aligns with Gröhn et al. (1998), who did not find any effect of season of calving on culling in dairy

Table 3. The 120-DIM univariable hazard model outcomes of each metabolic disease (complicated and uncomplicated, separately) diagnosed during the transition period in dairy cows

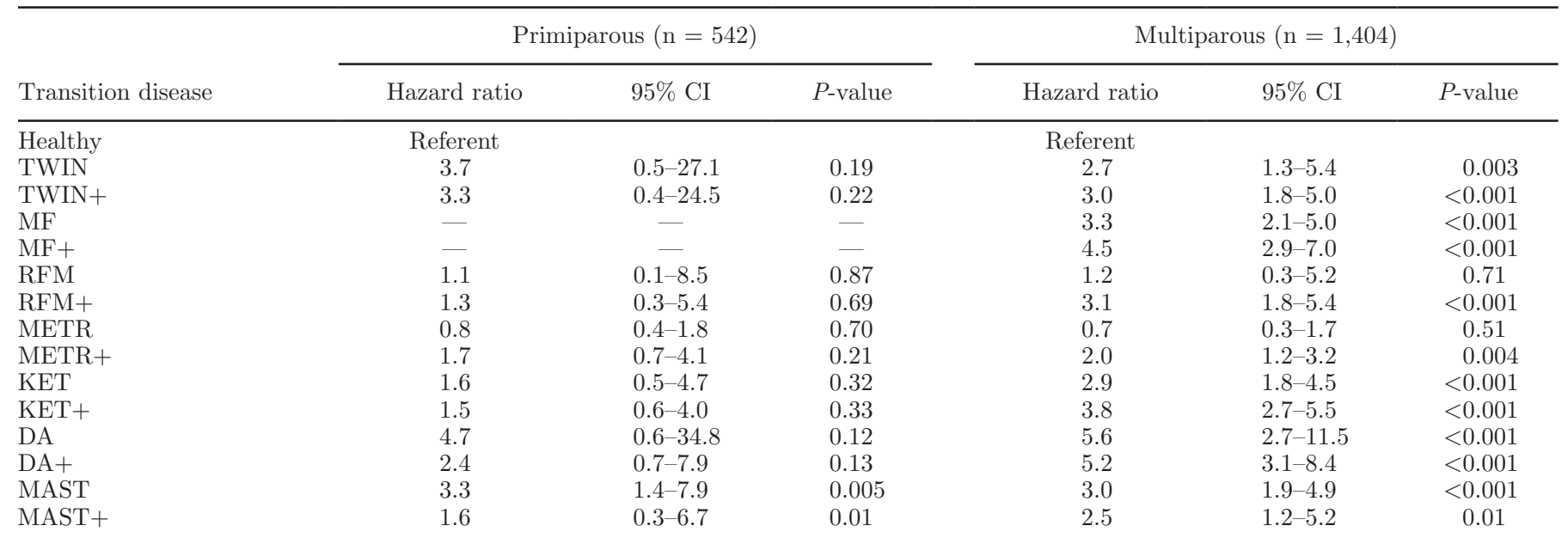

${ }^{1}$ TWIN $=$ twinning; $\mathrm{MF}=$ milk fever; RFM = retention of fetal membranes; METR = metritis; KET = ketosis; DA = displaced abomasum; MAST $=$ mastitis. $+=$ multiple metabolic diseases

${ }^{2}$ Hazard ratio $=$ chances of relative risk (constantly proportional) of culling per unit of time. Hazard ratio healthy $=1$. 
cows. Many studies have focused on the relationship between health disorders and culling (Martin et al., 1982; Dohoo and Martin, 1984; Oltenacu et al., 1984; Erb et al., 1985; Milian-Suazo et al., 1989; Bell et al., 2010; Chiumia et al., 2013). However, in those studies the MD were grouped into "reproductive" or "productive" categories. In the present study, the 120 DIM culling incidence and hazard ratio for culling relatively to each MD regardless of the final reason of culling were reported, thus taking into account an overall association between culling and each disease. The results of this study are indicative of the association of each MD as either predisposing risk factor (not inducing culling per se but having an indirect effect) or determining factor (having a direct effect) for culling. Moreover, MD may have different effects on culling depending on when they occur and when their effect on culling is observed. For example, DA often induces a poor prognosis and is associated with a subsequent decrease in milk yield, leading to a higher likelihood of immediate culling (Milian-Suazo et al., 1988; Gröhn et al., 1998).
However, for other diseases such reproductive disorders that do not affect milking ability, culling is generally delayed (Milian-Suazo et al., 1989; Seegers et al., 1998), causing a substantial lag between moment of observation and the moment of culling.

To evaluate the overall effect of MD during the transition period, the MD occurrence was analyzed in different ways. First, it was analyzes as the presence of an MD either complicated with another MD or not. The incidence of any combination of MD had a strong association with the culling decision in dairy farms. When a cow was classified as having a single MD or multiple MD or as healthy, the risk of being culled increased especially for the complicated cases (except for DA and MAST in multiparous cows and KET in primiparous cows). The incidences of most of the analyzed MD are in agreement with those reported in previous studies (LeBlanc et al., 2005; Ospina et al., 2010; Chapinal et al., 2012; Ribeiro et al., 2013; Dubuc and Denis-Robichaud, 2017). Only the incidence of KET (10.6\%) was lower (Dohoo and Martin, 1984; Berge and Vertenten,

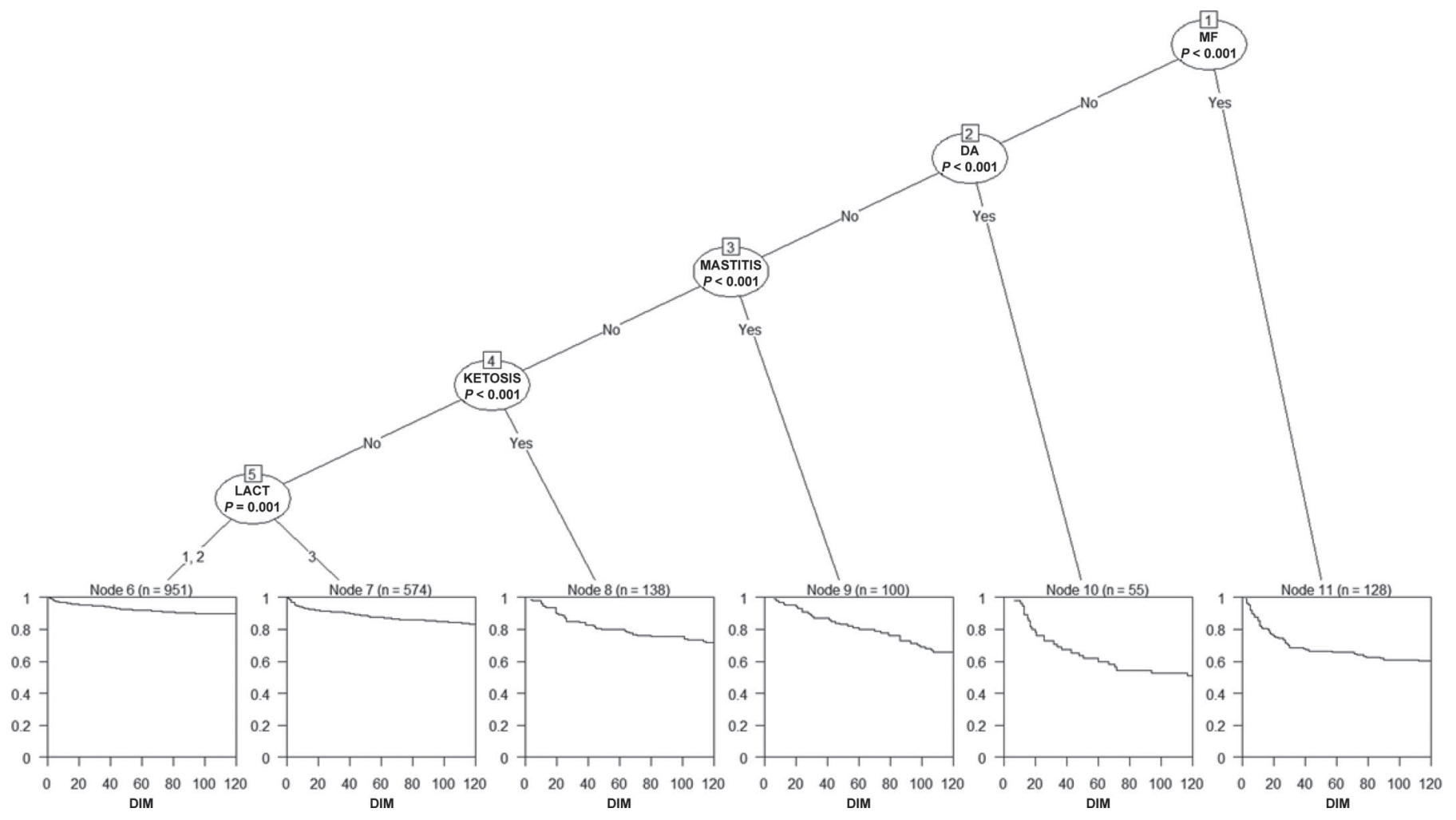

Figure 3. Conditional inference tree showing the hierarchical effect and the incidence of metabolic diseases (complicated and uncomplicated cases, together) diagnosed during the transition period on 120-DIM survival of dairy cows (total $\mathrm{n}=1,946)$. Node 1 ( $\mathrm{n}=128$ ) represents the first significant split for milk fever (MF) toward node 6 representing the remaining summation of remaining parity 1 and 2 cows $(\mathrm{n}=951$ ). Cows that presented metritis or retained placenta were found not significantly associated with 120 DIM culling risk. LACT = lactation; DA = displaced abomasum. 
2014), possibly due to the pre-established fresh cow protocol administered immediately after parturition (oral administration of $500 \mathrm{~mL}$ of propylene glycol).

Including multiple disease interactions in the Cox proportional hazard model is highly likely to violate the proportional hazards assumption of the current study. Especially with complex disease interactions, decision tree-based methods such as random forests can help identify relevant predictor variables. From the decision tree and random forest analyses, the most influential disease associated with a higher risk for culling within the first 120 DIM was found to be MF. This is in agreement with Gröhn et al. (1998), who reported that cows with MF were more likely to be culled during the first 30 DIM than cows without MF. Also, Dohoo and Martin (1984) and Milian-Suazo et al. (1988) found that MF increased the risk of culling, especially when the cow was already down. According to our data, the culling risk further increased when MF was complicated by the occurrence of another concomitant disease.

Although DA was the disease with the lowest incidence $(3.2 \%)$, it seemed to be the second highest ranked disease in the decision tree analysis, which was confirmed by the relative importance measures obtained from the random forest analysis. This is in contrast with previous studies performed on longer time frames, where udder disorders were declared to be the second most frequent culling reasons after reproductive disorders (Esslemont and Kossaibati, 1997; Seegers et al., 1998; Stevenson and Lean, 1998). Nevertheless, our data are in agreement with other studies that demonstrated DA as a prominent risk factor for culling, especially during early lactation (Gröhn et al., 1998; Rajala-Schultz and Gröhn, 1999). The survival rate of cows affected by DA was comparable in either complicated or uncomplicated cases, illustrating its strong association with culling irrespective of any other concomitant disease. Milk fever and DA showed the strongest association with decreased survival at 120 DIM, either impairing survival immediately or leading to suboptimal milk production, which subsequently resulted in early culling.

Mastitis appeared as the third cause of culling in the decision tree, contrary to the study by Gröhn et al. (1998), where MAST appeared as the disease that most influenced culling. Although cows are at risk for MAST throughout the entire lactation (Beaudeau et al., 1995), a recognized risk period for being culled for MAST is early lactation (Beaudeau et al., 1993; Gröhn et al.,

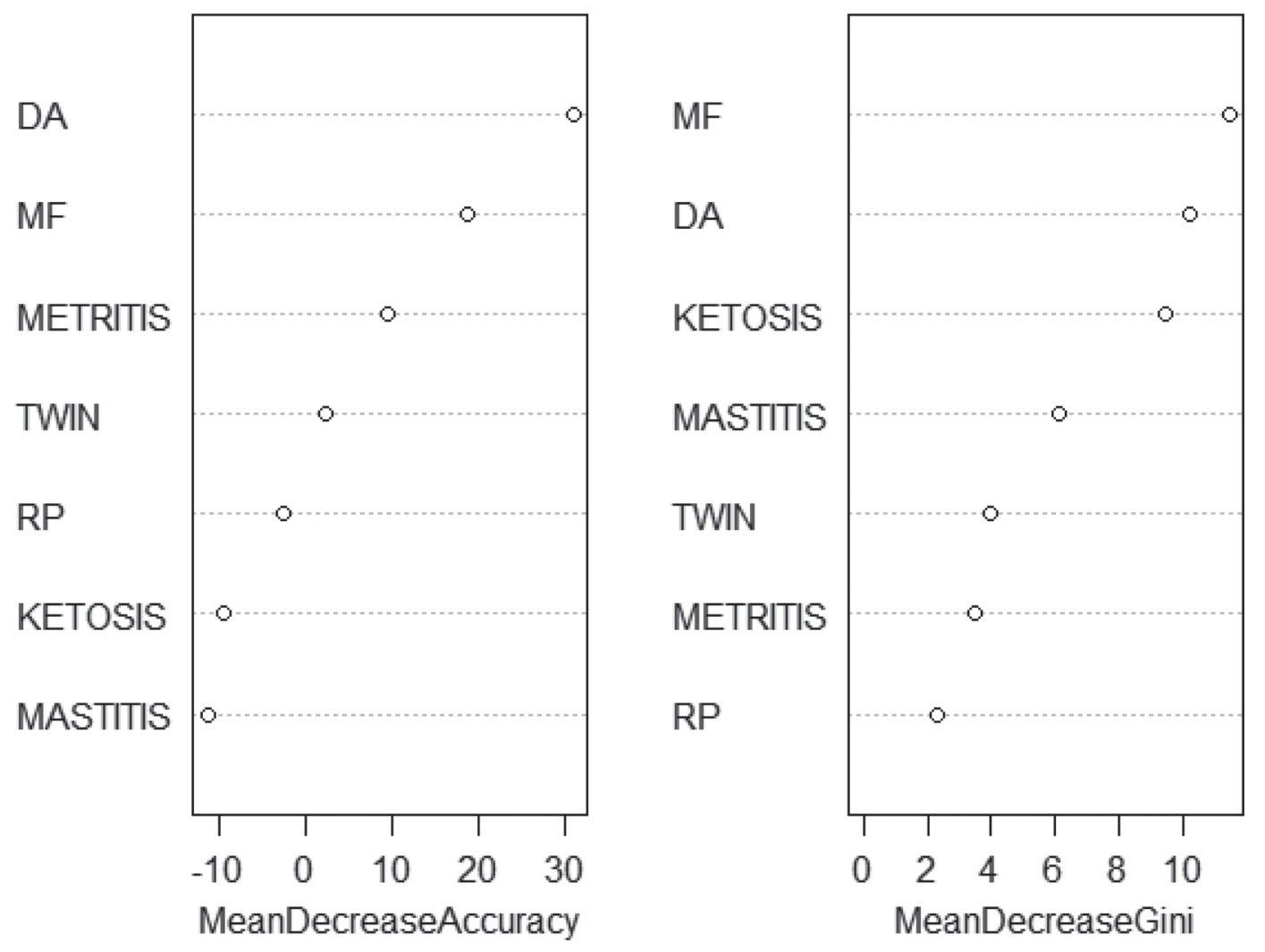

Figure 4. Mean decrease in accuracy (left) and Gini index (right) for each metabolic disease (complicated and uncomplicated cases, together) diagnosed during the transition period on the 120-DIM survival of dairy cows (total $\mathrm{n}=1,946$ ). DA $=$ displaced abomasum; MF $=$ milk fever; TWIN = twinning; $\mathrm{RP}=$ retained placenta. 
1998), mainly because of the severity of MAST (Beaudeau et al., 1995). Nevertheless, for MAST occurring after the peak of lactation, farmers may choose to treat first to allow the recovery of the cow and postpone her possible culling (Beaudeau et al., 2000). As stated by Seegers et al. (2003), the risk for a cow of being culled following the occurrence of clinical MAST mainly depends on the severity of the milk decrease and the farmer's anticipation concerning the future yield of the cow. Our data evaluated survival at 120 DIM, thus not considering the association between MAST and culling at the end of lactation. This may explain the fact the MAST is not the most influential MD associated with reduced survival at 120 DIM in the present study.

Ketosis was found to be the fourth cause of culling within 120 DIM. Importantly, about $60 \%$ of the KET cases in our study were complicated by another MD; this is in agreement with results from other studies (Oltenacu and Ekesbo, 1994; Berge and Vertenten, 2014). According to these authors, cows with KET were almost twice as likely to have MAST in early lactation. Leslie et al. (2000) reported that $28.6 \%$ of cows with prepartum KET subsequently developed MAST compared with $8.7 \%$ of cows without prepartum KET. Suriyasathaporn et al. (2000) hypothesized that the increased incidence of MAST in high-producing cows with negative energy balance could be due to the impairment of udder defense mechanisms related to hyperketonemia. However, Suthar et al. (2013) failed to detect an association between MAST and KET.

Twinning, although not considered a transition disease or $\mathrm{MD}$, is recognized as an important risk factor associated with other transition diseases or MD. It has been reported that cows delivering twins have 3 to 9 times higher risk of pregnancy loss during the first trimester of gestation (López-Gatius et al., 2002), longer calving to conception intervals, and higher culling rates (Bicalho et al., 2007) than singleton cows. AndreuVázquez et al. (2012) reported culling rates before 120 DIM of 16.1 and $8.7 \%$ for cows calving twins and singletons, respectively. Our results show that TWIN is associated with a high culling risk at 120 DIM (31.3\%). Interestingly, this association was independent from the presence or not of any other concomitant MD.

Two diseases did not influence survival at 120 DIM if uncomplicated: RP and METR. Results regarding RP are not surprising. Many studies reported no significant effect of RP on the culling risk (Dohoo and Martin, 1984; Erb et al., 1985; Dubuc et al., 2011; Haine et al., 2017c). Beaudeau et al. (1995) found that RP was even protective against culling, at least during the first lactation. Gröhn et al. (1998) suggested that the putative effect of RP may be indirect, through the mediation of poor reproductive performance. Retained placenta is known to be a risk factor for METR and endometritis (LeBlanc, 2008), resulting in negative effects on reproductive performance, and is therefore indirectly linked to decreased survival. According to our results, RP negatively affected survival only when complicated with another MD. The observation of culling at 120 DIM entails the exclusion of elective culling postponed at the end of lactation and due to poor (reproductive or productive) performance. This timing factor, together with the low incidence of uncomplicated RP in the present study $(\mathrm{n}=20)$, may have contributed to the lack of association between uncomplicated RP and culling.

Metritis was not significantly associated with the risk of culling in the present study, and this is in accordance with both old and more recent studies (Gröhn et al., 1998; Dubuc et al., 2010; Dubuc et al., 2011; Erb et al., 1985). However, complicated METR was associated with increased culling risk, but compared with other complicated MD, it presented the highest survival rate. However, an unfavorable association between METR and survival was found in other studies (Cobo-Abreu et al., 1979; Milian-Suazo et al., 1988; Oltenacu et al., 1990). Disease definition, duration of the follow-up period, sample size, and accounting for related diseases are important factors contributing to the discrepancy among results. In studies in which uterine infections increased culling, this was suggested to be the result of either decreased milk production or reduced reproductive performance (Gröhn and Rajala-Schultz, 2000; Overton and Fetrow, 2008). Another possible explanation for the lack of association between METR and survival at 120 DIM is the prompt diagnosis and treatment implemented in the transition management facility, reducing the severity of METR consequences.

\section{CONCLUSIONS}

The results of this study showed that, in general, MD are associated with increased culling during the first 120 DIM. Culling risk increased in most complicated MD (MD+). However, this cannot be generalized for DA, MAST, and TWIN, for which noncomplicated and complicated cases showed equal culling. The uncomplicated cases of RP and METR did not have an influence on the culling risk at 120 DIM. The decision tree analysis and the random forest analysis additionally provided evidence for the importance ranking of the MF and DA within the transition diseases and visualized their interaction with other diseases in the conditional inference tree. Given the presence of the transition management facility of the herd, the present results should be interpreted as related to a specific 
herd management. Overall, survival analysis and decision tree models can be efficiently applied to other dairy herds for survival evaluation.

\section{REFERENCES}

Andreu-Vázquez, C., I. Garcia-Ipierto, S. Ganau, P. M. Fricke, and F. Lopez-Gatius. 2012. Effects of twinning on the subsequent reproductive performance and productive lifespan of high-producing dairy cows. Theriogenology 78:2061-2070.

Beaudeau, F., V. Ducrocq, C. Fourichon, and H. Seegers. 1995. Effect of disease on length of productive life of French Holstein dairy cows assessed by survival analysis. J. Dairy Sci. 78:103-117.

Beaudeau, F., A. Henken, C. Fourichon, K. Frankena, and H. Seegers, 1993. Associations between health disorders and culling of dairy cows: A review. Livest. Prod. Sci. 35:213-236.

Beaudeau, F., H. Seegers, V. Ducrocq, C. Fourichon, and N. Bareille. 2000. Effect of health disorders on culling in dairy cows: A review and a critical discussion. Ann. Zootech. 49:293-311.

Bell, M. J., E. Wall, and G. Russell. 2010. Risk factors for culling in Holstein-Friesian dairy cows. Vet. Rec. 167:238-240.

Berge, A. C., and G. Vertenten. 2014. A field study to determine the prevalence, dairy herd management systems, and fresh cow clinical conditions associated with ketosis in western European dairy herds. J. Dairy Sci. 97:2145-2154.

Bicalho, R. C., S. H. Cheong, K. N. Galvão, L. D. Warnick, and C. L. Guard. 2007. Effect of twin birth calvings on milk production, reproductive performance, and survival of lactating cows. J. Am. Vet. Med. Assoc. 231:1390-1397.

Chapinal, N., S. J. LeBlanc, M. E. Carson, K. E. Leslie, S. Godden, M. Capel, J. E. P. Santos, M. W. Overton, and T. F. Duffield. 2012. Herd-level association of serum metabolites in the transition period with disease, milk production, and early lactation reproductive performance. J. Dairy Sci. 95:5676-5682.

Chiumia, D., M. G. Chagunda, A. I. Macrae, and D. J. Roberts. 2013 Predisposing factors for involuntary culling in Holstein-Friesian dairy cows. J. Dairy Res. 80:45-50.

Cobo-Abreu, R., S. W. Martin, R. A. Willoughby, and J. B. Stone. 1979. The association between disease, production, and culling in a university dairy herd. Can. Vet. J. 20:191-195.

De Vries, A. 2017. Economic trade-offs between genetic improvement and longevity in dairy cattle. J. Dairy Sci. 100:4184-4192.

Dohoo, I. R., and S. W. Martin. 1984. Disease, production and culling in Holstein-Friesian cows, V-Survivorship. Prev. Vet. Med. 2:771-784.

Dubuc, J., and J. Denis-Robichaud. 2017. A dairy herd-level study of postpartum diseases and their association with reproductive performance and culling. J. Dairy Sci. 100:3068-3078.

Dubuc, J., T. F. Duffield, K. E. Leslie, J. S. Walton, and S. J. LeBlanc. 2010. Definitions and diagnosis of postpartum endometritis in dairy cows. J. Dairy Sci. 93:5225-5233.

Dubuc, J., T. F. Duffield, K. E. Leslie, J. S. Walton, and S. J. LeBlanc. 2011. Randomized clinical trial of antibiotic and prostaglandin treatments for uterine health and reproductive performance in dairy cows. J. Dairy Sci. 94:1325-1338.

Erb, H. N., R. D. Smith, P. A. Oltenacu, C. L. Guard, R. B. Hillman, P. A. Powers, M. C. Smith, and M. E. White. 1985. Path model of reproductive disorders and performance, milk fever, mastitis, milk yield and culling in Holstein cows. J. Dairy Sci. 68:3337-3349.

Essl, A. 1998. Longevity in dairy cattle breeding: A review. Livest. Prod. Sci. 57:79-89.

Esslemont, R. J., and M. A. Kossaibati. 1997. Culling in 50 dairy herds in England. Vet. Rec. 140:36-39.

Fetrow, J., T. Ames, R. Farnsworth, S. Godden, P. Rapnicki, S. Stewart, and J. Vrieze. 2004. Minnesota's transition management facility: A private-public partnership in dairy veterinary education and applied research. J. Vet. Med. Educ. 31:368-371.

Fetrow, J., K. V. Nordlund, and H. D. Norman. 2006. Invited review: Culling: Nomenclature, definitions, and recommendations. J. Dairy Sci. 89:1896-1905.
Gröhn, Y. T., S. W. Eicker, V. Ducrocq, and J. A. Hertl. 1998. Effect of diseases on the culling of Holstein dairy cows in New York State. J. Dairy Sci. 81:966-978.

Gröhn, Y. T., and P. J. Rajala-Schultz. 2000. Epidemiology of reproductive performance in dairy cows. Anim. Reprod. Sci. 60-61:605614.

Grummer, R. R. 1995. Impact of changes in organic nutrient metabolism on feeding the transition cow. J. Anim. Sci. 73:2820-2833.

Hadley, G. L., C. A. Wolf, and S. B. Harsh. 2006. Dairy cattle culling patterns, explanations, and implications. J. Dairy Sci. 89:22862296

Haine, D., R. Cue, A. Sewalem, K. Wade, R. Lacroix, D. Lefebvre, J. Rushton, J. Arsenault, É. Bouchard, and J. Dubuc. 2017a. Culling from the actors' perspectives-Decision-making criteria for culling in Québec dairy herds enrolled in a veterinary preventive medicine program. Prev. Vet. Med. 148:1-9.

Haine, D., H. Delgado, R. Cue, A. Sewalem, K. Wade, R. Lacroix, D. Lefebvre, J. Arsenault, É. Bouchard, and J. Dubuc. 2017b. Marginal structural Cox model to estimate the causal effect of clinical mastitis on Québec dairy cow culling risk. Prev. Vet. Med. 147:124-131.

Haine, D., H. Delgado, R. Cue, A. Sewalem, K. Wade, R. Lacroix, D. Lefebvre, J. Arsenault, É. Bouchard, and J. Dubuc. 2017c. Contextual herd factors associated with cow culling risk in Québec dairy herds: A multilevel analysis. Prev. Vet. Med. 144:7-12.

Hare, E., H. D. Norman, and J. R. Wright. 2006. Survival rates and productive herd life of dairy cattle in the United States. J. Dairy Sci. 89:3713-3720.

Holzinger, A. 2015. Data mining with decision trees: Theory and applications. Online Inf. Rev. 39:437-438.

Hostens, M., J. Ehrlich, B. Van Ranst, and G. Opsomer. 2012. Onfarm evaluation of the effect of metabolic diseases on the shape of the lactation curve in dairy cows through the MilkBot lactation model. J. Dairy Sci. 95:2988-3007.

Ingvartsen, K. L., and K. M. Moyes. 2015. Factors contributing to immunosuppression in the dairy cow during the periparturient period. Jpn. J. Vet. Res. 63:S15-S24.

Jánosi, S., M. Kulcasár, P. Kóródi, L. Kátai, J. Reiczigel, S. J. Dieleman, J. A. Nikolic, G. Sályi, P. Ribiczey-Szabó, and G. Huszenicza. 2003. Energy imbalance related predisposition to mastitis in group-fed high-producing postpartum dairy cows. Acta Vet. Hung. 51:409-424.

LeBlanc, S. J. 2008. Postpartum uterine disease and dairy herd reproductive performance: A review. Vet. J. 176:102-114.

LeBlanc, S. J., K. E. Leslie, and T. F. Duffield. 2005. Metabolic predictors of displaced abomasum in dairy cattle. J. Dairy Sci. $88: 159-170$.

Leslie, K. E., T. F. Duffield, and Y. H. Schukken. 2000. The influence of negative energy balance on udder health. Pages 25-33 in Proc. Natl. Mastitis Council Regional Meetings, Madison, WI.

Liaw, A., and M. Wiener. 2002. Classification and regression by randomForest. R News 2:18-22.

López-Gatius, F., P. Santolaria, J. Yániz, J. Rutllant, and M. LópezBéjar. 2002. Factors affecting pregnancy loss from gestation day 38 to 90 in lactating dairy cows from a single herd. Theriogenology $57: 1251-1261$

Martin, S. W., S. A. Aziz, W. C. D. Sandals, and R. A. Curtis. 1982. The association between clinical disease, production and culling of Holstein Friesian cows. Can. J. Anim. Sci. 62:633-640.

Milian-Suazo, F., H. N. Erb, and R. D. Smith. 1988. Descriptive epidemiology of culling in cows from 34 herds in New York State. Prev. Vet. Med. 6:243-251.

Milian-Suazo, F., H. N. Erb, and R. D. Smith. 1989. Risk factors for reason-specific culling of dairy cows. Prev. Vet. Med. 7:19-29.

Moyes, K. M., T. Larsen, N. C. Friggens, J. K. Drackley, and K. L. Ingvartsen. 2009. Identification of potential markers in blood for the development of subclinical and clinical mastitis in dairy cattle at parturition and during early lactation. J. Dairy Sci. 92:5419-5428.

Mulligan, F. J., and M. L. Doherty. 2008. Production diseases of the transition cow. Vet. J. 176:3-9. 
Nyman, A.-K., U. Emauelson, K. Holtenius, K. L. Ingvartsen, T. Larsen, and K. Persson Waller. 2008. Metabolites and immune variables associated with somatic cell counts of primiparous dairy cows. J. Dairy Sci. 91:2996-3009.

Oltenacu, P. A., J. H. Britt, R. K. Braun, and R. W. Mellenberger. 1984. Effect of health status on culling and reproductive performance of Holstein cows. J. Dairy Sci. 67:1783-1792.

Oltenacu, P. A., and I. Ekesbo. 1994. Epidemiological study of clinical mastitis in dairy cattle. Vet. Res. 25:208-212.

Oltenacu, P. A., A. Frick, and B. Lindhe. 1990. Epidemiological study of several clinical diseases, reproductive performance and culling in primiparous Swedish cattle. Prev. Vet. Med. 9:59-74.

Ospina, P. A., D. V. Nydam, T. Stokol, and T. R. Overton. 2010. Association between the proportion of sampled transition cows with increased nonesterified fatty acids and $\beta$-hydroxybutyrate and disease incidence, pregnancy rate, and milk production at the herd level. J. Dairy Sci. 93:3595-3601.

Overton, M., and J. Fetrow. 2008. Economics of postpartum uterine health. Pages 39-43 in Proc. Dairy Cattle Reprod. Council Conv., Omaha, NE. Dairy Cattle Reproductive Council, Hartland, WI.

Pinedo, P. J., A. DeVries, and D. W. Webb. 2010. Dynamics of culling risk with disposal codes reported by Dairy Herd Improvement dairy herds. J. Dairy Sci. 93:2250-2261.

Rajala-Schultz, P. J., and Y. T. Gröhn. 1999. Culling of dairy cows. Part I. Effects of diseases on culling in Finnish Ayrshire cows. Prev. Vet. Med. 41:195-208.

Ribeiro, E. S., F. S. Lima, L. F. Greco, R. S. Bisinotto, A. P. Monteiro, M. Favoreto, H. Ayres, R. S. Marsola, N. Martinez, W. W. Thatcher, and J. E. P. Santos. 2013. Prevalence of periparturient diseases and effects on fertility of seasonally calving grazing dairy cows supplemented with concentrates. J. Dairy Sci. 96:5682-5697.

Rokach, L., and O. Maimon. 2014. Data Mining with Decision Tree. Series in Machine Perception and Artificial Intelligence. World Scientific Publishing Co. Pte. Ltd., Singapore.

Seegers, H., F. Beaudeau, C. Fourichon, and N. Bareille. 1998. Reasons for culling in French Holstein cows. Prev. Vet. Med. 36:257-271.

Seegers, H., C. Fourichon, and F. Beaudeau. 2003. Production effects related to mastitis and mastitis economics in dairy cattle herds. Vet. Res. 34:475-491.

Sheldon. I. M., G. S. Lewis, S. LeBlanc, and R. O. Gilbert. 2006. Defining postpartum uterine disease in cattle. Theriogenology 65:1516-1530.

Stevenson, M. A., and I. J. Lean. 1998. Descriptive epidemiological study on culling and deaths in eight dairy herds. Aust. Vet. J. $76: 482-488$

Sundrum, A. 2015. Metabolic disorders in the transition period indicate that the dairy cows' ability to adapt is overstressed. Animals (Basel) 5:978-1020.

Surivasathaporn, W.. C. Heuer, E. N. Noordhuizen-Stassen, and Y. H. Schukken. 2000. Hyperketonemia and the impairment of udder defense: A review. Vet. Res. 31:397-412.

Suthar, V. S., J. Canelas-Raposo, A. Deniz, and W. Heuwieser. 2013. Prevalence of subclinical ketosis and relationships with postpartum diseases in European dairy cows. J. Dairy Sci. 96:2925-2938.

Wittrock, J. M., K. L. Proudfoot, D. M. Weary, and M. A. G. von Keyserlingk. 2011. Metritis affects milk production and cull rate of Holstein multiparous and primiparous dairy cows differently. J. Dairy Sci. 94:2408-2412. 